\title{
Recurrent Endometrioma; Outcome of Medical Management with Dienogest
}

\author{
Fadia J Aizzi* \\ Department of Medicine, Al Mustansiriyah College of medicine, Iraq
}

*Corresponding author: Fadia J Aizzi, Assistant professor, Department of Medicine, Al Mustansiriyah College of medicine, Tel: +9647722629743; Email: fmjafalizzi@yahoo.co.uk

Received date: October 05, 2017; Accepted date: November 06, 2017; Published date: November 16, 2017

Copyright: (C) 2017 Aizzi FJ. This is an open-access article distributed under the terms of the Creative Commons Attribution License, which permits unrestricted use, distribution, and reproduction in any medium, provided the original author and source are credited.

Citation: Aizzi FJ (2017) Recurrent Endometrioma; Outcome of Medical Management with Dienogest. Eur Exp Biol. Vol. 7 No. 6:39.

\section{Abstract}

Background: Management of recurrent endometrioma should balance between the risk of unexpected hidden malignancy and the damaging effect of second surgery to ovarian tissue. Dienogest is a fourth generation of progestin and has been used in endometriosis with effective and save reports.

Patients and methods: Between April 2015 and August 2016, the recruitment was started to include women with symptomatic recurrent endometrioma after surgery, their ages between $18-40$ years. The adenxial masses had been evaluated by transvaginal ultrasound to prove the diagnosis which required the presence of ground glass echogenicity and one to four compartments and no papillary structures with detectable blood flow, after signing an informed consent, all patients received dienogest tablet $2 \mathrm{mg}$ daily for 52 weeks. Numeric pain scale, and transvaginal ultrasound were used to evaluate all patients on monthly basis in the first three months, then every three months.

Results: Twenty patients had been enrolled with minimum follow up after stopping the treatment is six months up to one year. The size of the cysts ranged from $3.2 \mathrm{~cm}$ up to 7 $\mathrm{cm}$, with mean size $5.46 \mathrm{~cm}$, after three months of treatment; mean numeric pain score was 2.5 versus 5.1 on presentation $(P<0.001)$, and the mean of largest diameter of the cyst became $3.1 \mathrm{~cm}$ versus $5.45 \mathrm{~cm}$ on presentation $(p<0.001)$. By the end of the 6 th month of treatment, we had residual cysts $(1.8 \mathrm{~cm})$ in two patients only which remain in their size until the end of treatment. With the end of follow up no report of recurrence of symptoms neither evidence of ultrasound features of recurrence.

Conclusion: Dienogest $2 \mathrm{mg}$ per day is a well-tolerated therapy for recurrent endometrioma with safe side effect profile. It can make the patient pain free and reduce the size of the cyst within three months.

Keywords: Recurrent endometrioma; Ovarian tissue; Clinician

\section{Introduction}

Endometriosis is a well-recognized gynecological problem which has a spectrum of presentations range from asymptomatic presentation, pain, infertility, to adnexal mass [1]. Endometriosis affects $6-10 \%$ of women of reproductive age, from these women, $17-44 \%$ have ovarian endometriosis, where there is a chocolate fluid -containing cyst within the ovary with ectopic endometrial tissue lining which is called ovarian endometrioma or chocolate cyst [2].

The presentation of patients with endometrioma also has the same spectrum of presentation of endometriosis in general, and the clinician should suspect the presence of this condition when he/she feels an adnexal mass, yet normal physical examination does not exclude the condition in clinically suspected cases [3]. The transvaginal ultrasound can diagnosis or role out the ovarian endometrioma, the diagnosis of ovarian endometrioma in premenopausal women depends on certain ultrasound characteristics which include: ground glass echogenicity and one to four compartments and no papillary structures with detectable blood flow [4], which had been adopted in the ESHRE guidelines [5].

The debate will start when we reach to the management of endometrioma, probably one can find no much debate in asymptomatic patient with typical ultrasound features, where the expectant management is the suitable option. The rate of unexpected malignancy has been found in $1 \%$ in patients with typical features of endometrioma [6], so other factors will influence the decision in an asymptomatic patients like the rate of growth, the age of patients, and personal and family history of breast and ovarian malignancies [7].

In symptomatic patients, the associated symptoms usually guide the choice of treatment, and the management options include medical, surgical, or both. The presence of endometriomas and the surgical management of them both have a damaging effect on the ovarian function and reserve [8], this fact creates the debate on the ideal management infertile women. The choices here will be either to go to IVF versus surgical management by laparoscopy [1].

The recurrence rate after surgical management ranges from $12-30 \%$ over a period of 2-5 years follow up [9], and it may be higher if we take into consideration the asymptomatic cases [3]. 
Regardless; the percentage of recurrence, the recurrent endometrioma represents a clinical challenge, where the surgery is generally discouraged due to high risk of damage to ovarian reserve; on the other hand, the recurrent endometrioma is associated with a significant risk of unexpected malignancy, particularly in patients older than 40 years [7].

This high recurrence rate may explain the growing evidence to support the postoperative use of medical treatment for at least 18-24 months, as one of the options for the secondary prevention of endometriosis-associated dysmenorrhea; this does not have proven the benefit for the secondary prevention of non-menstrual pelvic pain or dyspareunia [5].

If we exclude recurrent endometrioma after 40 years old, where the ovarian function preservation is not an issue, and the relatively high risk of malignancy, the management of recurrent endometrioma by surgical intervention is controversial where there is growing evidence that second surgical intervention may produce significant ovarian damage, in addition to difficulties that the second surgeon will face them due to adhesions [10].

With this dissatisfaction for the surgical intervention, there are different studies examined the efficacy of medical treatment, gonadotropin-releasing hormone (GnRH) agonists, danazol, aromatase inhibitors, and oral contraceptive pills. The use of these medical treatment has more than one limitations related to the tolerance, long-term side effect, and the cost $[5,10,11]$

Progestin has typically used in the treatment of endometriosis in those who are intolerant to combine pills. Dienogest is a fourth generation of this group and has been proved to be effective and safe in this indication $[12,13]$.

This study will evaluate the use of dienogest $4 \mathrm{mg}$ tablet in those who have recurrent endometrioma after surgery, and its efficacy in reliving the symptoms, and preventing recurrence. The study has a secondary endpoint of the efficacy in restoring pregnancy when the infertility is of concern.

\section{Patients and Methods}

This study has been approved by the scientific committee in the Obstetrics and Gynecology department in Al-Mustansyria College of medicine. Once it had been approved the recruitment started from April 2015 till August 2016.

The inclusion criteria were women with previous history of laparotomy for ovarian cyst and it was proved by histopathological examination as chocolate cyst, and they have presented at time of recruitment with symptoms suggestive of recurrence of endometrioma, and the last has been proved by transvaginal ultrasound with typical features of endometrioma, atypical features has been evaluate by pelvic MRI. The upper limit of the age was 40 years old. Those women who presented at time of recruitment with emergency state and they had a second surgery has been excluded, women planned to have pregnancy were excluded, and those with personal or family history of ovarian or breast cancer also were excluded, finally those women with atypical ultrasound and MRI criteria.
The ultrasound criteria for the diagnosis of ovarian endometriosis depended on the published ultrasound characteristics of ovarian endometrioma by Van Holsbeke, et al. which required the presence of ground glass echogenicity and one to four compartments and no papillary structures with detectable blood flow [5].

All women signed an informed consent after they had heard informations which included possible alternatives to Dienogest and possible side effect, and the rationale to use this drug and the duration of treatment.

The numeric pain rating scale $(0-10)$ was used to assess the response of dysmenorrhea, dyspareunia, and chronic pelvic pain to treatment, and was assessed monthly in the first three months and later every three months. The pain scale is showed in Table 1 [14].

Table 1: Numeric rating scale.

\begin{tabular}{|l|l|}
\hline Rating & Pain level \\
\hline 0 & No pain \\
\hline $1-3$ & Mild Pain (nagging, annoying, interfering little with daily activities) \\
\hline $4-6$ & Moderate Pain (interferes significantly with daily activities) \\
\hline $7-10$ & Severe Pain (disabling; unable to perform daily activities) \\
\hline
\end{tabular}

The largest diameter of the cyst was assessed by transvaginal ultrasound, and then checked monthly for the first three months, then every 3 months.

The dose of Dienogest was $2 \mathrm{mg}$ per day, to be taken after meal, in the same time every day, the missed dose can be taken with 12 hours of the usual time, and otherwise it should be recorded as missed dose. There was clear instruction to all patients to stop treatment and consult the medical services as soon as possible if there was any tenderness, or swelling in one leg.

The women were instructed to have monthly visit, and during each visit the pain scale was assessed, and any vaginal bleeding, gastrointestinal disturbance were recorded, then the compliance with the treatment was assessed. General examination, with vaginal examination to assess the local sign, then transvaginal ultrasound was done to assess the size of the cyst.

\section{Statistical analysis}

Anderson Darling test of normality was performed and all continuous variables follow normal distribution except duration of treatment was none-parametric, paired t test used to analyze the statistical difference from baseline to 3 months for pain score and cyst size, while chi square test used for categorical variables, Kaplan-Meier analysis used to estimate cumulative median duration of treatment for each treatment, the Logrank test used to calculate the $p$ value and compare the significant between each groups, all analysis performed using SPSS version 21.0 


\section{Results}

After the approval of this study, the recruitment was started and during the first six months of study 12 patients entered the study, and another 8 over the next seven months (beginning of August 2016), so total 20 patients had been enrolled and all of them has received treatment for 52 weeks, and the minimum follow up after stopping the treatment is six months up to one year.

The baseline characteristic of the study group is shown in Table 2, where we can see that 9 women (45\%) are between 35-44 years old. All of them have presented after two years from the date of the surgery, $90 \%$ of them before the mid of the third year, and the other before they finished the third year after surgery. The most common presentation was both dysmenorrhea and dyspareunia in 13 patients, and 8 patients have presented with infertility with or without pain.

Table 2: Baseline characteristics of study group.

\begin{tabular}{|c|c|c|c|}
\hline Criteria & Group & $\begin{array}{l}\text { Number of } \\
\text { patients }\end{array}$ & percentage \\
\hline \multirow{2}{*}{ Age (years) } & $\begin{array}{l}\text { More than, } 18 \text { less } \\
\text { than } 35\end{array}$ & 11 & $55 \%$ \\
\hline & 35 up to 40 & 9 & $45 \%$ \\
\hline \multirow{3}{*}{$\begin{array}{l}\text { Body mass } \\
\text { index }(\mathrm{kg} / \mathrm{m} 2)\end{array}$} & $<25$ & 6 & $30 \%$ \\
\hline & $25-30$ & 11 & $55 \%$ \\
\hline & $31-35$ & 4 & $20 \%$ \\
\hline \multirow{2}{*}{$\begin{array}{l}\text { Time since } \\
\text { surgery (years) }\end{array}$} & $2-2.5$ & 18 & $90 \%$ \\
\hline & $2.5-3$ & 2 & $10 \%$ \\
\hline \multirow{3}{*}{$\begin{array}{l}\text { Presenting } \\
\text { feature(s) }\end{array}$} & Dysmenorrhea & 6 & $30 \%$ \\
\hline & $\begin{array}{l}\text { Dysmenorrhea \& } \\
\text { dyspareunia }\end{array}$ & 13 & $65 \%$ \\
\hline & Infertility & 8 & $40 \%$ \\
\hline \multirow{2}{*}{ Size of cyst(cm) } & $\leq 5(3-5)$ & 7 & $35 \%$ \\
\hline & $>5(5-7)$ & 13 & $65 \%$ \\
\hline
\end{tabular}

The diagnosis was direct forward as all patients had reports of previous surgery which proved the diagnosis of chocolate cyst, and in the current presentation they have the classical picture of recurrent endometrioma by transvaginal ultrasound. The size of the cysts ranged from $3.2 \mathrm{~cm}$ up to $7 \mathrm{~cm}$, with mean size $5.46 \mathrm{~cm}$ and as Table 2 shows, 13 patients (65\%) had cyst size larger than $5 \mathrm{~cm}$.

After three months of treatment with dienogest, Table $\mathbf{3}$ shows the comparison in three parameters; mean numeric pain score, mean size of the cyst, and percentage of patients using analgesia, and we can see a significant improvements in all the three parameters after three months of treatment.

Table 3: Clinical and radiological progress three months from presentation.

\begin{tabular}{|l|l|l|l|}
\hline Criteria & $\begin{array}{l}\text { On } \\
\text { presentation }\end{array}$ & $\begin{array}{l}\text { 3 months on } \\
\text { treatment }\end{array}$ & P value \\
\hline Mean numeric pain score & 5.1 & 2.5 & $<0.001^{\mathrm{a}}$ \\
\hline $\begin{array}{l}\text { Mean size of cysts (cm); } \\
\text { mean } \pm \text { SD }\end{array}$ & $5.46 \pm 1.61$ & $3.1 \pm 0.65$ & $<0.001^{\mathrm{a}}$ \\
\hline $\begin{array}{l}\text { Percentage of patient using } \\
\text { analgesia }\end{array}$ & 100 & 65 & $0.004^{\mathrm{b}}$ \\
\hline $\begin{array}{l}\text { apaired test } \\
\text { bchi square test }\end{array}$ & & \\
\hline
\end{tabular}

The response of pain against time factor has been studied using Kaplan-Meier graph, in Figure 1, where we have two lines, one for those with less than $5 \mathrm{~cm}$ size and one with more than 5 $\mathrm{cm}$, in both lines we can see that after three months around $65 \%$ still not symptoms free, but after 5 months this cumulative percentage is reaching to zero.

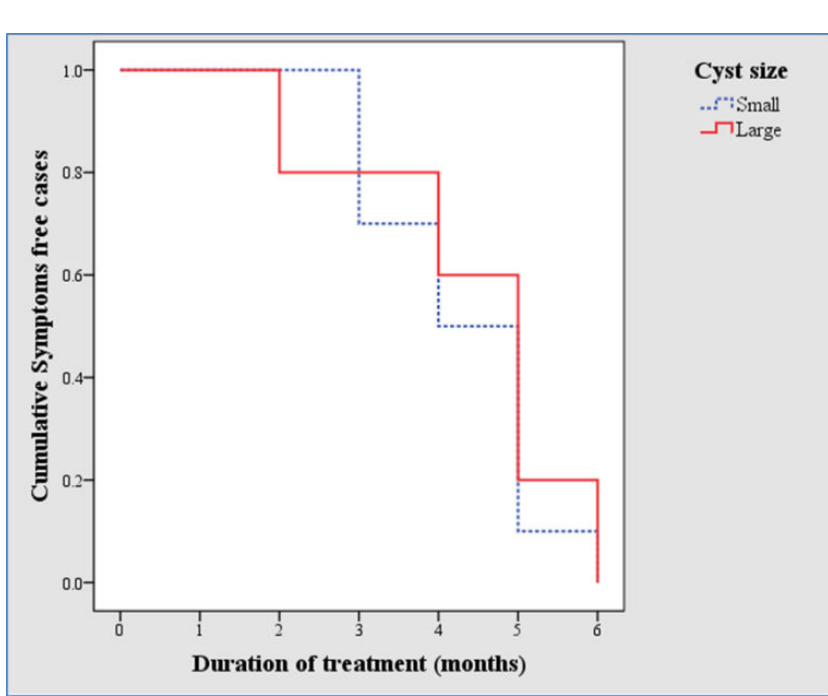

Figure 1: Kaplan-Meier graph for comparison of symptoms free patients in the two study groups, $\mathrm{N}=20$.

The cumulative cases that would be symptoms free with time run the same graph with small and large cyst and this is showed by log rank test in Table 4 where the P value is 0.6.

Table 4: Test of equality of the symptoms free distribution functions (DF=1).

\begin{tabular}{|l|l|l|l|}
\hline Statistic & $\begin{array}{l}\text { Observed } \\
\text { value }\end{array}$ & Critical value & p-value \\
\hline Log-rank & 0.275 & 3.841 & $0.600(\mathrm{NS})$ \\
\hline NS=not significant & & \\
\hline
\end{tabular}

The most frequent adverse events were the break through bleeding, and it occurred in $20 \%$ of patients and it occurred in first three months of treatment only. Two women (10\%) only had consulted for pain in the lower limbs, and Doppler done in all of them, which was normal. By the end of the 6th month of treatment, we had residual cysts $(1.8 \mathrm{~cm})$ in two patients only which remain in their size till the end of treatment. With the end of follow up no report of recurrence of symptoms neither 
evidence of ultrasound features of recurrence. Of the 8 patients who were complaining from infertility beside pain, two of them conceived after stopping treatment (52 weeks), while the other failed to have that.

\section{Discussion}

During the recruitment period, there were larger number than the number included in this study who had presented with recurrent endometrioma after surgery but it was not feasible to study the recurrence rate after surgery, although having 20 patients within 16 months with such condition points to the high rate of recurrence after surgery which was showed to be as high as $30 \%$ in different studies [5].

All the patients were not on maintenance treatment after their first surgery, this point needs to be considered in the future and should be evaluated where we can find increasing evidence for that, Vercellini $P$ et al in 2010, showed that the incidence of recurrence after surgical management of endometrioma was $10 \%$ only in those received contraceptive pills, and it was $40 \%$ in those who did not receive any treatment [15].

Choosing medical treatment for recurrent endometrioma will face argument for two reasons, first; is how much we are confident in excluding malignancy, second; cysts larger than 3 $\mathrm{cm}$ may carry risk of surgical emergencies. The first point can be resolved for our cohort for many reasons, the first reason is that all the patients are below 40 years, with negative family and personal history of malignancies, another point is that the duration between the surgery and the recurrence was more than 2 years which is long period for malignancy, plus the rate of growth before enrollment in the study and ultrasound features all were typical for endometrioma, and all the mentioned parameters should be considered in making the decision for endometrioma management [16]. Regarding the cysts size, definitely the cyst size play role in making the decision, and we can find clear decision for cysts larger than $10 \mathrm{~cm}$ to go for surgery, even in the presence of typical ultrasound features [17], and this due to higher possibility of having unexpected non benign growth [18]. Smaller than this size will be evaluated as a factor among several factors, and in our study the maximum size was $7 \mathrm{~cm}$, and the mean was $5.46 \mathrm{~cm}$, and many studies and trials had enrolled patients with same size [10]

After we have come across two arguments against medical treatment, we end with patients with symptomatic recurrent endometrioma with low risk of presence of malignancy, and low risk for urgent events that need surgery; here the issue of ovarian function preservation will play a big role in selecting the line of management. The second surgery will make more damage after the first one [19], and generally the surgery for the recurrent endometrioma is discouraged and oral contraceptive pills and progestins are the first line treatment $[5,20]$, and as stated above, all our patients carries low risk for malignancy.

This study had enrolled 8 patients with infertility, here the condition is more complicated, where the second surgery will affect ovarian function more, and the endometrioma affect it also, and this due to mechanical effect plus the inflammatory response secondary to the oxidative stress. Studies have showed that neither the presence of endometrioma nor the surgical removal of it affects the outcome of IVF, so it was recommended to go for IVF in women seeking pregnancy [20]. Unfortunately the IVF was not feasible to our patients and some refused to go through it. Taking in consideration the low rate of pregnancy with conservative approach which ranges from $0-25 \%$, and the damaging effect of second surgery, both factors encourage us to go through medical management, and after the treatment, 4 out of 8 with infertility conceived. However this approach may not attractive with the increasing availability of IVF in our country by which the patient can have pregnancy in short time.

The choices of medical treatment are several, and according to more than one guidelines, the selection should take in consideration the cost, side effect profile, and experience $[2,5]$. Dienogest $2 \mathrm{mg} /$ day was compared with triptorelin $3.75 \mathrm{mg}$ once every 4 weeks in a study for 16 weeks, and there was comparable response between the two groups, with similar side effect profile [21,22]. In another study from Japan, dienogest was used in 135 women with endometriosis for 52 weeks, around $73 \%$ of the women had responded at 24 weeks, and more than $90 \%$ at 52 weeks. Mid-cycle bleeding was the main side effect, occurring in $71.9 \%$ of women, these findings is comparable to our study.

\section{Conclusion}

Dienogest $2 \mathrm{mg}$ per day is a well-tolerated therapy for recurrent endometrioma with safe side effect profile. It can make the patient pain free and reduce the size of the cyst within three months.

\section{References}

1. Giudice LC, Kao LC (2004) Endometriosis. The Lancet 364: 1789-1799.

2. Practice Committee of the American Society for Reproductive Medicine (2014) Treatment of pelvic pain associated with endometriosis: a committee opinion. Fertil Steril 101: 927-935.

3. Bazot M, Lafont C, Rouzier R, Roseau G, Thomassin-Naggara I, et al. (2009) Diagnostic accuracy of physical examination, transvaginal sonography, rectal endoscopic sonography, and magnetic resonance imaging to diagnose deep infiltrating endometriosis. Fertil Steril 92: 1825-1833.

4. Van Holsbeke C, Van Calster B, Guerriero S, Savelli L, Paladini D, et al. (2010) Endometriomas: their ultrasound characteristics. Ultrasound Obstet Gynecol 35: 730-740.

5. Dunselman GA, Vermeulen N, Becker C, Calhaz-Jorge C, D'Hooghe T, et al. (2014) European Society of Human Reproduction and Embryology. ESHRE guideline: management of women with endometriosis. Hum Reprod 29: 400-412.

6. Muzii L, Angioli R, Zullo M, Panici PB (2005) The unexpected ovarian malignancy found during operative laparoscopy: incidence, management, and implications for prognosis. J Minim Invasive Gynecol 12: 81-89.

7. Valentin L, Ameye L, Franchi D, Guerriero S, Jurkovic D, et al. (2013) Risk of malignancy in unilocular cysts: a study of 1148 adnexal masses classified as unilocular cysts at transvaginal 
ultrasound and review of the literature. Ultrasound Obstet Gynecol 41: 80-89.

8. Alborzi S, Keramati P, Younesi M, Samsami A, Dadras N (2014) The impact of laparoscopic cystectomy on ovarian reserve in patients with unilateral and bilateral endometriomas. Fertility and Sterility 101: 427-434.

9. Jones KD, Sutton CJ (2002) Recurrence of chocolate cysts after laproscopic ablation. J Am Assoc Gynecol Laprosc 9: 315-320.

10. Muneyyirci-Delale O, Anopa J, Charles C, Mathur D, Parris R, et al. (2012) Medical management of recurrent endometrioma with long-term norethindrone acetate. International Journal of Women's Health 4: 149-154.

11. Agarwal SK, Foster WG (2015) Reduction in Endometrioma Size with Three Months of Aromatase Inhibition and Progestin AddBack. BioMed Research International.

12. Strowitzki T, Faustmann T, Gerlinger C, Seitz C (2010) Dienogest in the treatment of endometriosis-associated pelvic pain: a 12-week, randomized, double-blind, placebo-controlled study. Eur J Obstet Gynecol Reprod Biol 151: 193-198.

13. Strowitzki T, Marr J, Gerlinger C, Seitz C (2010) Dienogest is as effective as leuprolide acetate in treating the painful symptom of endometriosis: a 24-week randomized, multicentre, open-label trial. Hum Reprod 25: 633-641.

14. Bourdel N, Alves J, Pickering G, Ramilo I, Roman H (2015) Systematic review of endometriosis pain assessment: how to choose a scale? Hum Reprod Update 21: 136-152.

15. Vercellini P, Somigliana E, Viganò P, De Matteis S, Barbara G (2010) Post-operative endometriosis recurrence: a plea for prevention based on pathogenetic, epidemiological and clinical evidence. Reprod Biomed Online 21: 259-265.

16. di Tucci ML, di Feliciantonio M, Galati G, Verrelli L, di Donato V, et al. (2017) Management of Endometriomas .Semin Reprod Med 35: $25-30$.

17. Donnez J, Nisolle M, Gillet N, Smets M, Bassil S, et al. (1996) Largeovarian endometriomas. Hum Reprod 11: 641-646.

18. Valentin L, Ameye L, Franchi D, Guerriero S, Jurkovic D, et al. (2013) Risk of malignancy in unilocular cysts: a study of 1148 adnexal masses classified as unilocular cysts at transvaginal ultrasound and review of the literature. Ultrasound Obstet Gynecol 41: 80-89.

19. Garcia-Velasco JA, Somigliana E (2009) Management of endometriomas in women requiring IVF: to touch or not to touch. Hum Reprod 24: 496-501.

20. Practice Committee of the American Society for Reproductive Medicine (2012) Endometriosis and infertility: a committee opinion. Fertil Steril 98: 591-598.

21. Cosson M, Querleu M, Donnez J (2002) Dienogest is as effective as triptorelin in the treatment of endometriosis after laparoscopic surgery: results of a prospective, multicenter, randomized study. Fertil Steril 77: 684-692.

22. Momoeda M, Harada T, Terakawa N (2009) Long-term use of dienogest for the treatment of endometriosis. J Obstet Gynaecol Res 35: 1069-1076. 